\title{
POLITIZAÇÃO, AMBIENTALIZAÇÃO E DESENVOLVIMENTO TERRITORIAL EM RESERVAS EXTRATIVISTAS
}

\author{
Maria José da S. A. Teisserenc*
}

\begin{abstract}
Esse artigo, resultante de pesquisas no contexto de duas Resex marinhas do estado do Pará, Mãe Grande do Curuçá e São João da Ponta, trata de mudanças que vêm ocorrendo no poder local, relacionadas à criação de áreas protegidas na Amazônia brasileira. Observa-se, então, uma politização dos desafios locais, manifesta como resultado do trabalho realizado nos Conselhos Deliberativos, nos quais a mobilização das comunidades e o engajamento de seus representantes possibilitam debates que dizem respeito ao desenvolvimento de seu território conforme exigências ambientais. Trata-se de uma dinâmica significativa de um desenvolvimento territorial que se beneficia de uma ambientalização geral gerada com a criação das Reservas e do valor deliberativo dos compromissos de membros conselheiros como uma instância política. Essa situação constitui interessante oportunidade de análise das relações entre práticas de democracia local de tipo deliberativo e uma orientação de desenvolvimento que inspira o engajamento dos atores locais em instituições novas, como os Conselhos Deliberativos.
\end{abstract}

Palavras-chave: Politização e Ação Pública. Desenvolvimento Territorial. Ambientalização. Poder Local. Participação e Deliberação.

\section{INTRODUÇÃO}

Neste artigo o objetivo é apreciar em que medida a contribuição das Reservas Extrativistas ao desenvolvimento sustentável do território, por meio da deliberação, interpela o modelo de desenvolvimento imposto pela globalização. Em nossas pesquisas, ${ }^{1}$ a Resex tem sido considerada como um instrumento de política pública (teisserenc, 2009), cuja eficácia está relacionada à capacidade de promover um desenvolvimento territorial orientado pelas exigências ambientais a partir do reconhecimento das populações tradicionais como atores integrantes do território e implicados em sua gestão participativa. Nesse sentido os resulta-

\footnotetext{
* Universidade Federal do Pará. Faculdade de Ciências Sociais. Programa de Pós-Graduação em Sociologia e Antropologia (PPGSA).

Campus Central da UFPA. Av. Augusto Corrêa, 01. Guamá. Cep: 66075-110. Belém - Pará - Brasil.mjaq@uol.com.br

${ }^{1} \mathrm{O}$ financiamento dos trabalhos de pesquisa dos quais resulta este artigo deu-se através de dois projetos. Um, já finalizado, Procad NF "Territórios Emergentes da Ação Pública Local e Desenvolvimento Sustentável na Amazônia Brasileira" (2010-2015), financiado pela CAPES - O segundo projeto em andamento, "Participação social em unidades de conservação na Amazônia brasileira", coordenação da profa. Tânia Guimarães Ribeiro (FACSO e PPGSA UFPA), é financiado pelo CNPq. A autora está vinculada aos referidos projetos, a cujo apoio material propiciado e convivência acadêmica estimulante agradece.
}

dos de pesquisa até aqui alcançados permitem constatar que a implementação das Reservas faz-se acompanhar de uma politização dos desafios locais no trabalho realizado no Conselho Deliberativo. Essa politização se explica pela natureza desse trabalho, que consiste em criar condições de desenvolvimento sustentável do território da Reserva. Do mesmo modo, essa politização se explica pelo caráter deliberativo dos debates e dos compromissos do Conselho em atender exigências ambientais. De fato, responder ao desafio de criar condições de desenvolvimento de um território que satisfaça tais exigências necessita que os membros do Conselho estejam de acordo sobre a natureza dessas exigências, em função das características do território, e que tal seja traduzido em termos de projetos e de instrumentos e dispositivos de gestão.

Considerando, então, a orientação exposta, apresentaremos primeiramente a Reserva Extrativista em termos de desenvolvimento territorial, em um contexto de ambientalização, para, em seguida, tratar de como se manifesta a politização dos desafios locais a partir do trabalho do Conselho Deliberativo. 
Em seguida, será apreciado em que medida as mudanças que acompanham essa politização põem em xeque o modelo de desenvolvimento.

A base empírica referida neste trabalho resulta de pesquisas conduzidas nesses últimos anos em duas das doze Resex marinhas criadas no estado do Pará, complementada com pesquisas realizadas anteriormente em dois territórios em redesenvolvimento situados na Europa (Teisserenc, 2002). As duas Resex Marinhas em questão são as de Mãe Grande do Curuçá e a de São João da Ponta, ambas criadas, respectivamente, nos municípios vizinhos de Curuçá e São João da Ponta, no ano de 2002. A criação dessas duas Reservas se beneficiou de uma mobilização importante das comunidades, de modo mais conflitual e caótico em Curuçá do que em São João da Ponta, na sequência de uma série de acontecimentos favoráveis à organização das comunidades, com o apoio da igreja católica. Tal mobilização favoreceu igualmente o engajamento dos parceiros institucionais da Reserva - em particular, agências de serviços técnicos, universidades e diversos tipos de experts, solicitados para resolver problemas de várias ordens na medida em que se impuseram. Nos dois casos, a audiência atual da Reserva junto às populações locais se explica, em grande parte, como produto da práहै tica de deliberação do Conselho. Trata-se de um : trabalho que se traduz por um melhoramento das condições de vida nas comunidades, por um reconhecimento de suas competências proj dutivas, ${ }^{2}$ assim como pela operacionalização de uma gestão participativa de seu território. Nos N dois casos, a criação da Reserva e o trabalho nela realizado têm contribuído para uma mu\& dança política inesperada nas eleições municiiे pais de 2008, quando chegaram ao poder equipes favoráveis ao projeto da Resex. ${ }^{3}$

${ }^{2}$ Reconhecimento que, para a Resex, é justificado pelos saberes e práticas, bem como pelos valores que os inspiram.

I ${ }^{3}$ Em São João da Ponta, quando das eleições de 2008, é o presidente da Mocajuim - associação dos usuários da Resex - que foi eleito prefeito. Trata-se de uma pessoa que desempenhou um papel importante no processo de criação da Resex. Em Curuçá chegou ao poder uma equipe constituída por um herdeiro de importante família da região, industrial
Essa mudança importante no poder local oportunizou a análise, nas duas Resex, dos efeitos em termos de desenvolvimento do território da Reseva no sentido da satisfação de exigências e reivindicações relacionadas à sua criação - exigências ambientais e reivindicações do direito à terra e ao uso dos recursos naturais do território. Estávamos conscientes de que tais efeitos não podiam unicamente ser apreciados do ponto de vista econômico, social e ambiental e que eles comportavam uma dimensão política, o que foi constatado nos resultados das eleições municipais de 2008. É considerando, portanto, a dimensão política que dirigiremos a análise para o trabalho do Conselho Deliberativo. ${ }^{4}$ Portanto, nossa investigação sobre as duas Resex privilegiou a maneira como os debates, no seio do Conselho, têm levado em conta os desafios do desenvolvimento de seu território em relação às exigências ambientais. Tais debates, pouco a pouco, por conseguinte, têm produzido, nos conselheiros, representantes das comunidades, uma percepção política de seu engajamento, valorizado pela legitimidade conferida pelas suas competências como saberes nativos, pela nova retórica que eles adquirem na prática dos debates públicos e pela qualidade

da pesca, dinâmico e ambicioso, preocupado em modernizar a gestão local, e um técnico da Emater, militante católico com destacado envolvimento na criação da Resex.

${ }^{4}$ Em Curuçá, o trabalho do Conselho é realizado a partir de um compromisso político entre o movimento social e o poder local, enquanto que, em São João da Ponta, ele é realizado com base em uma complementaridade política entre a prefeitura e o Conselho Deliberativo. Nas eleições de 2012, em São João da Ponta, onde mais da metade dos eleitores são membros da associação de usuários da Resex, o prefeito é reeleito, enquanto que, em Curuçá, isso não ocorreu. Nesse município, o Conselho Deliberativo, que havia tido desempenho importante no mandato municipal anterior, foi rapidamente relegado a um segundo plano, confirmando, com isso, que, em termos de desenvolvimento territorial, as mudanças apresentam muitas vezes um caráter aleatório, pois elas percorrem caminhos caóticos no seio dos quais os compromissos e coalizões dos atores locais desempenham papel preponderante. A situação de São João da Ponta, atualmente, reforça nosso ponto de vista. É significativo que, na continuidade de mudanças institucionais, desde a instituição do Conselho Deliberativo, o engajamento dos atores locais, líderes das comunidades (presidentes de associações locais, membros do Conselho Deliberativo etc.) tenham aceito participar de um seminário experimental de qualificação, ocasião para refletir em conjunto sobre as condições, os conteúdos e a contribuição de seu engajamento local como líderes associativos e comunitários e como membro do Conselho Deliberativo. 
dos projetos que concretizam seu engajamento e dos quais se esperam resultados em termos de desenvolvimento sustentável do território. Essas investigações têm sido complementadas pelos primeiros resultados de um seminário de qualificação dos líderes locais de São João da Ponta, realizado em atendimento a uma demanda do gestor da Resex, um técnico do ICMBio, o que nos permitiu melhor compreender a implicação dessas pessoas em uma gestão participativa e sustentável do território no âmbito do Conselho e o sentido político de seu engajamento.

\section{RESEX: instrumento de política pú- blica e desenvolvimento territorial na ambientalização}

\section{Resex: instrumento de política pública}

A Resex, como instrumento de política pública, no sentido entendido por Pierre Lascoumes e Patrick Le Galès (Lascoumes; Le Gales, 2007), foi abordada em um artigo (Teisserenc, 2009), no qual se mostrou a originalidade desse instrumento, considerando sua história e os objetivos que lhe são atribuídos, na medida em que se trata de um dos raros instrumentos de política pública concebida e experimentada pelo movimento social em parceria com experts e cientistas, operacionalizada em um contexto nacional e internacional particularmente favorável. ${ }^{5}$

Da história da criação do instrumento Resex, consideraremos aqui a ideia de uma "área historicamente ocupada por populações que se utilizam de produtos florestais para subsistência e comercialização, dependentes da utilização de produtos nativos da floresta

${ }^{5}$ No plano nacional, é o fim da ditadura e o retorno da democracia de um país endividado e, por isso, muito dependente das potências estrangeiras; no plano internacional, é a emergência da questãoo ambiental e os debates entre os ecologistas radicais, defensores da preservação da natureza em áreas interditas à intervenção humana, e os defensores da conservação e gestão da biodiversidade em áreas protegidas, comprometidos com a satisfação de novas exigências ambientais. e realizam uma exploração ecologicamente sustentada" (Allegretti, 2008, p. 17), que se concretiza em um projeto inscrito "em um horizonte do possível (Almeida, 2004, p. 48), para permitir ao conjunto das populações ditas tradicionais permanecer na floresta graças a uma reforma agrária que respeita sua organização econômica e social e graças também à modernização de seu modo de produção e de seus métodos de trabalho, com o apoio de experts e de pesquisadores. Incontestavelmente, Chico Mendes e o movimento social que se organizou em torno dele souberam utilizar o argumento das exigências ambientais - um argumento de um novo tipo no contexto dos anos de 1980 - para "resistir à proletarização forçada dos seringueiros" (Almeida, 2004, p. 48) pela reivindicação de uma reforma agrária e de uma exploração da biodiversidade justificada pela luta conduzida por populações em defesa de um território que eles ocupavam e exploravam de modo não predatório, em harmonia com a natureza. Tal reivindicação contribuiu para uma ambientalização dos desafios locais. Não se limitando à reivindicação dos direitos coletivos à terra, visavam "também a uma possibilidade de, sem deixar de ser seringueiros, se tornar antes de tudo, cidadãos, políticos, gerentes de associação, professores e pesquisadores" (Almeida, 2004, p. 49).

Essa experiência excepcional é assumida pelas autoridades públicas brasileiras em um contexto de retorno da democracia e de estruturação de organismos e dispositivos dentro do Estado brasileiro, orientado pelas exigências do desenvolvimento sustentável, fazendo da Resex um dos símbolos dessa política, ao integrá-la no Sistema Nacional de Unidades de Conservação (Santilli, 2005). Assim, o projeto Reserva Extrativista é transformado em um instrumento de política pública, entendido como capaz de responder às exigências do desenvolvimento sustentável de um território com uma rica biodiversidade pela implementação de um regime especial de gestão, apoiado pelos poderes públicos federais objetivando 
proteger o modo de vida, a cultura e os saberes e práticas das populações extrativistas tradicionais, respeitadas às exigências ambientais ${ }^{6}$ (Aubertin; Pinton, 2006, p.7).

Em meio às ferramentas adotadas pelo Estado para satisfazer às reivindicações do movimento social e facilitar o êxito das Resex, figura o Conselho Deliberativo. Nele têm assento, de maneira paritária, representantes das comunidades implicadas e das instituições parceiras da Resex, encarregados de pôr em marcha uma gestão participativa, utilizando, para tal, os recursos disponibilizados pelo Estado (recursos financeiros e serviços técnicos especializados), e dispositivos como os diagnósticos ambientais, territoriais e socioeconômicos territoriais e os Planos de Utilização e ou de Gestão. O caráter deliberativo desse Conselho lhe confere um estatuto quase político, uma vez que seu papel não se limita a uma gestão técnica do território.

\section{Instrumento a serviço do desenvolvimento territorial}

A ideia de "desenvolvimento territorial" aqui referida inspira-se em inúmeras experiências de territórios europeus em redesenvolviڤ. mento, no âmbito de processos de desindus․ trialização e expansão da sociedade neoliberal. Pesquisas sobre essas experiências resultaram em uma concepção do desenvolvimento terrif torial $^{7}$ (Teisserenc, 2002). como um processo

ㄱำ ${ }^{6}$ De fato, na concepção de Reserva Extrativista, foi reconhecida às populações extrativistas a legitimidade para ocupar

$?$ a terra onde viviam e explorar os recursos naturais, pois

^ seus saberes e práticas as predispunham a respostas ade-

¿. quadas aos desafios ambientais. Esse reconhecimento cons-

titui o fundamento de um contrato que permite às comuni-

คे dades "capables de s'organiser et de s'imposer sur la scène

$>$ publique" [e decididas a satisfazer os objetivos ambientais]

"d'acquérir une reconnaissance politique et identitaire, ainsi

के que des droits fonciers." (Aubertin; Pinton, 2006, p. 6).

$\stackrel{\pi}{\geq} 7$ Baseamo-nos em uma concepção do desenvolviemnto స్ territorial que se impôs na Europa nos anos de 1980, mar. cada pelas mudanças econômicas e sociais concretizadas, I. especialmente, em uma desindustrialização generalizada,

త acompanhada de uma elevação rápida das taxas de desem-

$\wp$ prego, colocando, então, em xeque o modelo de desenvol-

vimento da sociedade industrial, que havia prevalecido

desde o fim da Segunda Guerra. Em tal contexto, o de-

senvolvimento territorial se colocou como uma resposta dinâmico, caracterizado por uma diversificação e um enriquecimento dos projetos e das iniciativas de um território, a partir da mobilização de um conjunto de recursos tanto materiais quanto imateriais, em particular de seus recursos humanos (Greffe, 1984). ${ }^{8}$ A experiência desses territórios em redesenvolvimento mostra que tal mobilização de atores e recursos só é eficaz, no longo prazo, se for apoiada em um projeto de desenvolvimento que sirva de referência a iniciativas e ações de vários tipos, promovidas por essa dinâmica.

Reencontramos, na concepção de Resex como instrumento de política pública, a ideia de mobilização do conjunto dos recursos do território a serviço do enriquecimento e da diversificação das iniciativas e dos projetos, uma mobilização que se beneficia notadamente de um reconhecimento das populações locais, ditas tradicionais, e de seus saberes e práticas em relação a seu território. ${ }^{9}$ Reencontramos igualmente, nessa concepção, a importância do projeto de território na forma de um Plano de Utilização e (ou) Gestão de uma Reserva, no qual são codificados não somente os compromissos dos atores locais com a gestão da biodiversidade de seu território, baseada nas orientações ambientais, mas também o conjunto dos acordos entre esses atores e as regras de várias ordens, que põem em xeque a aplicação desses acordos. ${ }^{10}$

à crise econômica e social que atravessava a sociedade e que, portanto, buscava um novo modelo de desenvolvimento do tipo bottom-up e como o resultado de reformas emanadas do Estado central. Na França, o essencial dessas reformas consistiu em uma descentralização dos poderes políticos por meio de uma transferência de competências do Estado para outros níveis administrativos coletivo-territoriais. E, para tal, foram conferidos a esses outros níveis recursos e autonomia para conduzirem ações públicas territoriais. Em um contexto de crise geral, falava-se de desenvolvimento territorial sempre que essas reformas em curso foram assumidas por coletivos de atores locais mobilizados para defender o futuro de seu território.

${ }^{8}$ Essa concepção do desenvolvimento do território não se refere a um modelo, como foi o caso da sociedade industrial. ${ }^{9}$ No caso das duas Reservas em análise, trata-se do melhoramento de certas técnicas de pesca e de extração dos caranguejos, dos modos de gestão dos recursos e de sua comercialização, do desenvolvimento de iniciativas de exploração de recursos medicinais ou de produção de bijuterias por grupos de mulheres, ou ainda de atividades no setor de turismo comunitário.

${ }^{10}$ No contexto europeu, o projeto de território se impôs como um instrumento codificado que concretiza o acordo dos atores locais para cooperar no ordenamento e desen- 


\section{Em um contexto de ambientalização}

Por ambientalização entendemos aqui, no sentido dado por José Sérgio Leite Lopes, como "um processo histórico de construção de novos fenômenos, [...] relacionado à construção de uma nova questão social, de uma nova questão pública”. ${ }^{11}$ Empiricamente, esse processo se manifesta por mudanças na forma dos conflitos sociais e nas estratégias dos atores locais, pelos argumentos por eles colocados para explicar e justificar esses conflitos e pelo início de institucionalização da sua gestão. No contexto amazônico, onde predomina uma ambientalização "verde", ${ }^{12}$ isso se apresenta como uma maneira nova de apreender os problemas locais em termos de exigências ambientais, originando debates que levam especialmente a uma visibilidade e a uma legitimidade dos conflitos socioambientais locais (Leite Lopes, 2006, p. 36). ${ }^{13} \mathrm{O}$ resultado é uma maneira nova de compreender o território e seus desafios em termos de desenvolvimento sustentável, o que oferece aos atores novos argumentos para justificar compromissos, individual e (ou) coletivamente.

De acordo com Leite Lopes, a influência da educação ambiental sobre populações locais, quando se trata de interiorização de preocupações ambientais, traduz-se pela adoção de novas condutas e de novos valores, en-

volvimento de seus territórios e que permite ao Estado justificar os recursos atribuídos na proporção dos investimentos necessários à realização desse projeto.

${ }^{11}$ Em contextos de territórios industrializados, aos quais se refere particularmente Leite Lopes, trata-se de conflitos nos quais se opõem empresa e meio ambiente e, dentro deles se dividem os trabalhadores.

${ }^{12}$ Para Leite Lopes, a ambientalização marrom diz respeito aos efeitos da poluição ambiental das empresas no território, enquanto que a ambientalização verde põe em causa muito mais os desafios do futuro dos territórios amazônicos pela desflorestação e exploração predatória da biodiversidade.

${ }^{13}$ Esse ponto de vista converge, sem dúvida, para a percepção de Enrique Leff (2006, p. 455), para quem a ambientalização das situações locais se explica pelo novo ambientalismo social, caracterizado por uma reivindicação das populações tradicionais em termos de direito agrário e de reconhecimento de suas competências específicas para operar um modo de produção e de gestão do território susceptível de responder às exigências ambientais. Para Leff, nesse novo ambientalismo, há a demanda de democratização do poder local e de suas instituições a partir de práticas participativas que interpelem o funcionamento dessas instituições e o sistema de poder. riquecendo o modo de compreender o território. A experiência das duas Resex aqui tratadas demonstra que essa interiorização de preocupações ambientais é também o resultado de aprendizagens coletivas em debates locais que se desenvolvem particularmente no seio dos Conselhos Deliberativos, nos quais se exercita a participação.

As experiências europeias referidas por Leite Lopes, nas conclusões de seu artigo ora considerado, levaram-no a perceber que a gestão dos conflitos socioambientais remete a uma "pista de mobilização para a participação via [reabilitação da] memória e identidade social local” (Lopes, 2006, p. 59), o que consiste em transformar "um passivo ambiental decorrente de um processo de desindustrialização (prédios, depósitos, imóveis e terrenos abandonados, porém controlados pelas fábricas e usinas) em fonte de patrimônio material, imaterial, histórico e cultural" (Lopes, 2006, p. 58). Esse modo de compreender o redesenvolvimento do território confere grande imporância ao reconhecimento da identidade das polulações através da implementação de propostas que mobilizam suas referências simbólicas e seu capital, ligados a uma cultura fortemente enraizada no território. É, sem dúvida, em contextos amazônicos, uma mobilização similar que se busca estimular nas Resex, quando se trata da participação e da deliberação como oportunidades de politização, o que, em seguida, será discutido.

Pode-se ir um pouco além, evocando a perspectiva segundo a qual, nesse contexto de ambientalização, o desenvolvimento territorial conduzido por atores locais com ferramentas que favorecem a emergência de uma concepção deliberativa da gestão local - em particular, o Conselho Deliberativo, os diagnósticos locais e o plano de gestão - poderia constituir o embrião de um novo modelo de desenvolvimento? Essa perspectiva animou muitos militantes do desenvolvimento territorial nos anos de 198090 na Europa. Do mesmo modo, no espírito de Chico Mendes e do movimento social no qual 
ele se apoiou, a busca de um modelo alternativo foi claramente presente. A apropriação dessa experiência original pelo Estado brasileiro e sua generalização como instrumento de política pública necessariamente modificou a natureza do projeto inical, em proporções dificilmente avaliáveis, o que justifica reconhecer que a Resex constitui, sim, um instrumento de política pública a serviço de um desenvolvimento territorial sustentável. Mas permanece como hipotética a ideia de que a experiência das Resex poderia colocar em xeque o modelo de desenvolvimento que se impôs ao conjunto do planeta. Portanto, trata-se de uma questão aberta a investigações complementares sobre o fenômeno da politização dos desafios locais.

\section{POLITIZAÇÃO PELA APLICAÇÃO DA AGENDA AMBIENTAL À SITUAÇÃO DAS POPULAÇÕES TRADICIONAIS}

Os debates suscitados pela criação e organização de uma Reserva, particularmente no Conselho Deliberativo, dão origem a compromissos de toda ordem, que dizem respeito não somente à gestão, mas também a seu desenvolvimento no futuro. A hipótese aqui privilegiada considera que, em um contexto favorecido

ક̊ pelas mudanças políticas nas duas Reservas, a : partir das eleições de 2008, tais debates, centrados nas exigências ambientais, dão origem a uma politização dos atores locais, o que se i explica pelo seu caráter deliberativo e pela legitimidade da existência da Resex como um instrumento de política pública.

\section{O que se está entendendo por "politização"?}

Existem, pelo menos, duas abordagens da politização. A primeira, a mais frequentemente utilizada, a considera como consequência do tratamento de situações problemáticas pelas instâncias políticas nacionais, qualquer que seja o quadro institucional, bem como o nível territorial compreendido. Assim, para as situações abordadas, considera-se que, na medida em que a lei no 9.985, que institui o Sistema Nacional de Unidades de Conservação, visa, entre outros objetivos, a "proteger os recursos necessários à subsistência das populações tradicionais" que, anteriormente, não se beneficiavam de nenhum estatuto reconhecido, sobretudo em termos de uso da terra, ${ }^{14}$ a resposta trazida pela Resex, de natureza jurídica, econômica e social, certamente é também de natureza política, uma vez que é apresentada como um instrumento de política pública. Assim sendo, a politização aparece como um dos efeitos dos debates que se produzem a partir de uma agenda política onde se propõe o tratamento dessas situações, com debates que, no caso aqui estudado, opõem os cientistas aos políticos e a uma administração das questões relativas à identificação das populações beneficiárias e à sua categorização. Por exemplo, por que qualificar de "tradicionais" as comunidades compostas de pessoas heterogêneas em suas origens e pertencimentos? Esses debates se concluem geralmente pela ideia de que a resposta proposta pelas autoridades políticas, mesmo se jamais justificada de um ponto de vista científico, aparece como pertinente de um ponto de vista político na medida em que traz uma solução, evidentemente mais ou menos eficaz, a uma situação problemática.

A segunda maneira de apreender a politização é no sentido dado por Jacques Lagroye, isto é, a maneira como, em um território, os atores locais conseguem transformar relações sociais, suas formas de intercâmbio e comunicação, alguns de seus compromissos, em - tradução nossa - "elementos ou regras do espaço político" e conseguem também "construir uma argumentação, uma retórica para disto tratar" (Lagroye, 2003, p. 12). Essa concepção da politização se refere à existência de um espaço público no qual se desenrolam debates com base

${ }^{14}$ Diferentemente, por exemplo, das populações quilombolas, para as quais a Constituição Federal propõe princípios jurídicos para reparar injustiças cometidas a partir da escravidão. 
em uma retórica inspirada pelas exigências do bem comum. Para Jacques Lagroye, tal requalificação de todos os tipos de práticas sociais em atividades políticas é o resultado - tradução nossa - "de um acordo prático entre agentes sociais", dispostos a transgredir as regras tradicionais do funcionamento da ordem local (Lagroye, 2003, p. 360).

Consideramos que essas duas formas de politização não correspondem a vias distintas, justificando analisar os efeitos independentemente, pois elas são complementares e interdependentes. Nesse sentido, somos levados a considerar suas interferências a partir da situação das duas Reservas, objetivando apreciar o que essas experiências revelam do modelo de desenvolvimento para o qual contribuem a promover.

\section{Politização: a questão ambiental na ordem do dia}

Nos debates aos quais temos nos referido, cientistas e políticos se opõem quanto à denominação de populações tradicionais para os beneficiários do projeto da Resex como um instrumento de política pública. Essa denominação está no SNUC e identifica segmentos populacionais considerados aptos a contribuir com a conservação dos recursos naturais, a promover uma gestão sustentável de seu território e que, portanto, "devem ser respeitados e valorizados seus conhecimentos e sua cultura, promovendo-as social e economicamente". ${ }^{15}$

Justificava esses debates o fato de que, diferentemente de indígenas e quilombolas, os beneficiários das Resex, as populações tradicionais, não possuíam uma identidade étnica específica $^{16}$ Capobianco et al. 2001. A Resex apare-

${ }^{15}$ Lei 9.985, Art. $4^{\circ}$, XIII.

${ }^{16}$ Ver importante contribuição ao debate de Manuela Carneiro da Cunha em "Populações tradicionais e conservacão ambiental", publicado em Biodiversidade na Amazônia brasileira: avaliação e ações prioritárias para a conservação, uso sustentável e repartição de benefícios, organização de João Paulo. Tais populações são caracterizadas por uma heterogeneidade étnica e, até então, não tinham sido beneficadas com um reconhecimento jurídico e um direito territorial. Ver, a propósito, o Decreto Federal n. 6.040, de ce, assim, como oportunidade de conferir a esse segmento da população um reconhecimento, permitindo-lhes o benefício de um direto ao uso da terra, com o objetivo de fazer valer sua capacidade de gestão de um território reconhecido pela riqueza de sua biodiversidade.

Em um artigo sobre os problemas e as contradições das políticas de desenvolvimento sustentável na Amazônia, Philippe Léna evoca as dificuldades encontradas pela administração brasileira para qualificar as populações rurais da Amazônia e explica, assim, porque "as categorias são sempre ambíguas, misturando as categorias nativas, sociológicas e políticas" (Léna, 2002, p. 18). Segundo Philippe Léna, essas ambiguidades ocorrem porque as categorias são definidas em função de particularismos sempre que problemáticas contribuem para "uma identidade construtiva". Tais particularismos nada possuem de sociológico e se referem a categorias "nativas". Desse modo, os poderes públicos se reapropriam dessas denominações para identificar os beneficiários de suas políticas e, por conseguinte, "os particularismos são transformados em categoria política”, obrigando as populações concernidas a entender que "não há outro caminho para obter o reconhecimento dos seus direitos universais senão conquistar o reconhecimento de seus particularismos" (Léna, 2002, p. 19).

Debates parecidos podem ser percebidos envolvendo cientistas e políticos em torno da questão dos direitos das populações quilombolas. Diferentemente das populações tradicionais, aquelas compartilham, evidentemente, uma história comum, o que justifica sua identificação. Contudo, para os antropólogos, os quilombolas constituem uma "categoria administrativa” (Boyer, 2010, p. 716-717), considerada cientificamente pouco pertinente, pois "o interesse de mantê-la é antes de tudo político”. (Almeida, 2004, p. 16). A adoção dessa categorização pode ser compreendida

07 de fevereiro de 2007, através do qual se instituiu a Política Nacional de Desenvolvimento Sustentável e Povos e Comunidades Tradicionais. 
como o resultado de um tipo de compromisso cuja razão única é a vontade do conjunto dos parceiros de tornar incontestável "a existência dos quilombolas na cena política”, para que essas minorias obtenham "o reconhecimento político necessário para conquistar o direito à terra" (Lima, 2002, p. 18).

Nos dois casos, o dos quilombolas e o das populações tradicionais, tal compromisso entre políticos e cientistas em relação à identificação desses segmentos populacionais como beneficiários de ações públicas iniciadas na sequência da execução de agenda política pautada em suas situações consideradas como problemas contribui para uma "politização das identidades” (Berno de Almeida, 2008, p. 147), manifesta como aspecto de um trabalho mais geral de politização de suas situações.

Esse trabalho de politização se manifesta, do lado dessas populações organizadas como comunidades, pela vontade de "se constituírem como sujeitos políticos” para satisfazerem suas reivindicações territoriais. No caso dos quilombolas, o território reivindicado é aquele de seus ancestrais e, no caso das populações tradicionais, trata-se do território que ocupam e, para assim continuar, se comprometem com um desenvolvimento regido por exigências ambientais.

Assim se apresenta a primeira forma de politização a partir de uma agenda política que contempla a situação de determinadas populações, levando-as a uma mobilização para reinvindicar estatuto, direito à terra e ao reconhecimento de sua identidade, de seu território etc. para responder aos desafios do desenvolvimento sustentável de seus territórios.

\section{POLITIZAÇÃO DE ATORES LOCAIS, DELIBERAÇÃO E DESENVOLVI- MENTO SUSTENTÁVEL}

Já indicamos, de acordo com Jacques Lagroye, que a segunda forma de politização que ora nos interessa põe em xeque uma requalificação das ações engajadas pelos atores locais. Trata-se de ações sociais, econômicas e culturais que se impõem ao mesmo tempo como ações políticas a partir de um acordo entre os atores locais. Tal acordo depende, notadamente, de uma preocupação dos políticos em - tradução nossa - "adotarem novos comportamentos legitimados pela 'exigência de proximidade' e as supostas expectativas dos representantes da sociedade civil" (Lagroye, 2003, p. 371). Concretamente, vejamos como se procede a essa politização a partir do Conselho Deliberativo em cada uma das duas Reservas - Mãe Grande de Curuçá e São João da Ponta.

\section{Politização no Conselho Deliberativo}

Da análise realizada nos dois Conselhos, ressalta-se, de início, que os debates desenvolvidos em seu seio levam a uma visibilidade maior dos conflitos locais, ao serem apresentados como conflitos socioambientais, graças à legitimidade do Conselho Deliberativo, instituição portadora da Reserva Extrativista como instrumento de política pública. No caso de Mãe Grande de Curuçá, a legitimidade do Conselho foi reforçada com a participação pessoal do prefeito, ${ }^{17}$ e as questões tratadas não se restringiram ao território da Reserva. Assim, pouco a pouco, o conjunto dos problemas do território municipal foi sendo abordado, e o Conselho Deliberativo se impôs como um lugar privilegiado de expressão da sociedade civil de Curuçá e de lideranças políticas locais, capaz de exercer influência nas dinâmicas do

${ }^{17} \mathrm{Na}$ maior parte dos Conselhos Deliberativos das Reservas Extrativistas, a Prefeitura é representada pelo secretário municipal do meio ambiente. 
município, o que foi observado com bastante profundidade por Vasconcelos (2010, p. 121). Esse reconhecimento das competências expandidas do Conselho pode ser interpretado como um primeiro resultado da requalificação de suas atividades, na medida em que as decisões que foram sendo tomadas se beneficiavam da mesma legitimidade do poder local. O que comprova o ponto de vista de um conselheiro comunitário que considera os debates no Conselho como "ocasião de experiências democráticas fortes" e que as decisões tomadas têm permitido um reequilíbrio em favor dos interesses das populações representadas. Essa ideia de reequilíbrio se refere a problemas postos pela coexistência, em um mesmo município, de espaços como o território municipal fora da Reserva, eminentemente urbano, e o território da Reserva, onde profundas desigualdades se verificam. Na mesma perspectiva, outro conselheiro comunitário mencionou o Conselho como o lugar onde "territórios políticos se expressam".

Essa situação nova nos parece a consequência do acordo implícito entre os atores sobre o papel político que desempenha o Conselho, um papel manifesto nos debates sobre a gestão municipal sob a condução de seus membros que, por essa razão, tendem a se considerar como "novos atores políticos", cujo objetivo é "conciliar forças antagônicas" e "se colocar à disposição de uma política ambiental ultrapassando disputas de poder através da implementação de ações coletivas”. Esses argumentos podem confirmar que, em última instância, é o engajamento dos atores locais em ações de desenvolvimento do território que conforta e legitima o trabalho de politização.

Nesse trabalho de politização, são igualmente significativas as dificuldades encontradas pelos representantes das comunidades para satisfazerem às exigências de um bom funcionamento do Conselho. Em particular, entre os conselheiros, há desigualdades de acesso às informações e de conhecimento dos dossiês, bem como dificuldades de serem compreendidos na agenda dos problemas encontrados, de formalizarem e enunciarem suas demandas e reivindicações nos termos de um interesse geral. O que essas dificuldades revelam é a complexidade da "institucionalização da deliberação compreendida no sentido de sua inserção no aparelho político" (Gohn, 2007, p. 57).

As dificuldades identificadas e enunciadas comprovam também que os conselheiros buscam dominar uma linguagem e uma argumentação novas, que compreendem as exigências ambientais como objetivos de suas lutas e, ao mesmo tempo, contribuam para renovar a retórica de seus discursos. ${ }^{18}$

\section{Politização em ação local}

Consideremos, mais precisamente, as condições oferecidas aos conselheiros comunitários para assumirem plenamente seu novo papel no Conselho Deliberativo que, no desempenho de suas funções, deve criar condições favoráveis à coprodução de ações locais sob a forma de projetos de desenvolvimento de um território. Portanto, são eles - os conselheiros - os atores implicados em um trabalho em escala territorial que se mostra cada vez mais político. Foram observados os resultados de um seminário ${ }^{19}$ de formação, realizado no âmbito

${ }^{18} \mathrm{O}$ funcionamento de espaços públicos como os Conselhos Deliberativos, em parte, corresponde à definição de Jürgen Habermas (1987) como lugares de debates onde opinião e alternativas de ação são produzidas e, por conseguinte, contribuem para uma "politização ordinária" da ação local. Essa politização se traduz, no plano cognitivo, pela mudança nos discursos dos atores engajados e se beneficia das aprendizagens individuais e coletivas nos intercâmbios e confrontos dentro desses espaços. Nossas análises sobre o que está em jogo nesses espaços vão ao encontro do pensamento de Axel Honneth (1996) quanto à reabilitação da dinâmica das lutas sociais e o engajamento dos atores cujas motivações e formas de resistência correspondem também a reivindicações de reconhecimento justificadas em convicções morais.

${ }^{19}$ Em uma primeira sessão de trabalho com os dez participantes desse seminário, dez pontos foram identificados para serem trabalhados: quatro deles relativos às modalidades de controle da aplicação das regras ambientais coletivamente enunciadas; dois sobre as mudanças de práticas e inovações de acordo com as exigências ambientais; dois relativos ao poder local e à ausência de servicos públicos; um sobre a mobilização das comunidades e de seus membros; e o último sobre a sensibilização das crianças para as exigências ambientais e a conscientização das famílias. 
de uma ação de extensão universitária vinculada à pesquisa, com os membros do Conselho Deliberativo da Resex de São João da Ponta e líderes de comunidades. Entre os dez pontos identificados, objeto de aprofundamento em sessão posterior, quatro parecem especialmente significativos do trabalho de politização em um contexto de deliberação.

Na origem do convencimento, da organização e da participação está o reconhecimento dos recursos trazidos pela Resex e de iniciativas voltadas para a construção de casas e melhoramento das existentes, para o conforto cotidiano, para elevação do nível de vida, para o acesso à água potável etc. Existe também a ideia de que, para os extrativistas, esses primeiros resultados se explicam, em grande parte, pelo apoio dos parceiros exteriores na negociação dos acordos de gestão e elaboração das regras que respondem às exigências ambientais, com o objetivo de facilitar a produção individual e coletiva das comunidades e de seus membros. Nessa maneira de apresentar a situação, ressoa a ideia de que a mobilização das comunidades está fundada na afirmação de uma identidade extrativista, que se traduz na existência de acordos e de regras resultantes de práticas profissionais inspiradas nos saberes nativos.

Significativo dessa situação nova é a - maneira como os conselheiros concebem a implementação dessas regras e seu controle. Retomemos, para isso, o exemplo das práticas profissionais inspiradas nos saberes nativos, que se impuseram com o objetivo de atender às exigências do desenvolvimento sustentável. Essas práticas são legitimadas pelos acordos $\stackrel{2}{2}$ de gestão nos quais seu uso é autorizado. Os $\therefore$ acordos, resultantes de um trabalho coletivo of e participativo, constituem, para os membros

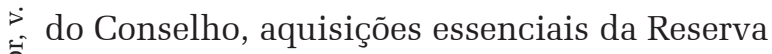
desde sua criação e são considerados como um tipo de "bem comum" a ser por eles protegido Fi e defendido através da aplicação das regras e de seu controle. ${ }^{20}$

${ }^{20}$ Essas regras a todos se impuseram a partir do seu reconhecimento pelo Ibama, órgão inicialmente responsá-
Essa consciência de um bem comum sinaliza uma nova ordem local emergente, expressa no fato de os líderes locais não mais se contentarem em apreender os problemas a partir da situação de cada comunidade, mas a partir do conjunto das populações do território municipal. ${ }^{21}$

No que concerne à ideia de um bem comum, o que remete à de "interesse geral de caráter local”, a importância atribuída à identidade, às regras e aos valores partilhados - que interpelam não somente a organização do trabalho, mas também a vida cotidiana das populações - constitui um indicador desse trabalho de politização. Trata-se de um trabalho que explica por que esses atores engajados em práticas participativas chegam a se entender sobre a ideia de um bem comum, pois sua defesa e valorização devem contribuir para o desenvolvimento sustentável de um território a partir da mobilização de suas populações.

Efetivamente, quando se aprofundou, com os participantes do seminário, as condições da mobilização, ela foi mostrada como o resultado de dois fatores essenciais. O primeiro é que a mobilização se dá para defender algo que é comum ao conjunto, do qual cada um pode tirar proveito a título pessoal. Portanto, se bem comum em questão for protegido e valorizado, ele permitirá o acesso a bens individuais em termos de habitação, instrumentos de trabalho e apoio técnico, em uma conjuntura na qual o governo federal, ao criar um sistema de bolsas (família, escola, verde etc), contribuiu para ampliar as vantagens concedidas às populações locais. O segundo diz respeito ao fato de

vel pela direção da Reserva. O respeito a elas depende do controle que a sociedade local assume tendo em vista um desenvolvimento adequado de seu território. Esse controle, correspondente a um trabalho de regulação compete ao coletivo da sociedade local pelo viés do Conselho Deliberativo, o que habitualmente se constituiu como um trabalho da competência político-administrativa do município.

${ }^{21}$ Tal se comprova quando um grande número de problemas identificados pelos participantes do seminário, como as questões de gestão lo lixo, de educação ambiental, de mobilização das populações, não são específicas às comunidades usuárias da Resex e seus membros. São problemas cujas soluções não advém unicamente de acordos, de regras e compromissos dentro das comunidades e que, por isso, são eficazes na implicação do conjunto dos cidadãos do município. 
que a mobilização se dá igualmente em torno de projetos, como é o caso do aperfeiçoamento de coleta, acondicionamento e transporte do caranguejo, garantindo a reprodução da espécie e a redução de perdas. Do mesmo modo, assiste-se a um início de mobilização em torno da produção de ostras. ${ }^{22}$ Essas práticas, inspiradas nos saberes nativos, se apresentam como o resultado da adaptação de práticas tradicionais às exigências de uma gestão sustentável do espaço das Reservas graças ao apoio científico e técnicos de novos parceiros, como ONGs, universidades, serviços especializados do Estado etc. A mobilização atraída por esse tipo de iniciativas é típica de uma ação que associa atores locais voluntários e seus parceitos em um trabalho conjunto de valorização dos recursos da biodiversidade do território. Essa mobilização confirma a importância da relação entre as dinâmicas de desenvolvimento territorial e os desafios da ambientalização das situações locais em um contexto de deliberação favorecido pela legitimidade de um instrumento de política pública como a Resex.

As críticas formuladas no âmbito do Conselho com respeito ao poder local são igualmente significativas das mudanças em curso. Essas críticas não são dirigidas a esse poder como uma instância superior, exterior às comunidades, como é geralmente o caso quando os cidadãos ordinários falam dos políticos e do poder local. Esse poder local é percebido muito mais como um parceiro que é criticado por suas carências e com o qual se busca melhorar a maneira de trabalhar conjuntamente para resolver problemas que, como a educação, a saúde, a gestão da água, a gestão do lixo, entre outros, concernem a todos os cidadãos e constituem competências da agenda dos políticos locais.

\footnotetext{
${ }^{22}$ Evidentemente, a exploração de ostras é uma atividade menos tradicional que a do caranguejo. Mas tudo leva a crer que, em futuro próximo, considerando o entusiasmo que o consumo de ostras começa suscitar nas grandes cidades do centro-sul do país, a atividade também venha a ser chamada assim. E, com a expansão de um mercado consumidor sensível à certificação de produtos - como caranguejos e ostras originários de trabalho realizado por populações tradicionais, respeitadas as exigências ambientais -, é possível imaginar um percurso nessa direção a ser trilhado por essa produção em Curuçá e São João da Ponta.
}

\section{CONCLUSÕES: governança am- biental e novo modelo de desenvol- vimento?}

O que é possível concluir da experiência dessas duas Reservas que, na sequência de uma mudança política com as eleições de 2008, foram favorecidas por um reconhecimento que lhes permitiu, com o trabalho de seus Conselhos Deliberativos, integrar o jogo político local? ${ }^{23}$ Nos dois casos, o projeto Resex se impôs como um projeto de desenvolvimento territorial, na medida em que mobilizou, de maneira conjunta, os atores e o conjunto dos recursos do território, em particular, sua rica biodiversidade. Nos dois casos, a mobilização dos atores foi favorecida pela legitimidade conferida pela Resex como um instrumento de política pública e pelo aporte de contribuições externas estimulantes dessa mobilização. Nos dois casos, sem dúvida, o desafio ambiental é que fundamenta o contrato e o projeto de desenvolvimento. Nos dois casos, os atores implicados nas instâncias de gestão da Resex, em particular no Conselho Deliberativo, vivem mudanças que põem em xeque suas competências, o significado de seu papel e de suas missões, mas também sua representação do território e sua concepção do funcionamento das instituições. Essas mudanças se traduzem, notadamente, por novas relações entre as instituições do poder local, como a Prefeitura e a Câmara, que põem em causa uma requalificação dos compromissos dos líderes locais implicados na gestão da Reserva, uma requalificação que procuramos abordar em termos de politização. ${ }^{24} \mathrm{Tal}$ politização se impõe como

${ }^{23}$ Essa integração e esse reconhecimento não são produzidos da mesma maneira nas duas Reservas. São João da Ponta conta com uma estabilidade política e esse não é o caso de Curuçá.

${ }^{24} \mathrm{O}$ funcionamento das duas Reservas, desde sua criação, prova que os processos analisados não são homogêneos. Eles dependem da situacão de cada um dos territórios. Assim, a maioria da qual dispõe o prefeito de São João da Ponta contribui para uma estabilidade eleitoral favorável ao estabelecimento de relações de cooperação entre o Conselho Deliberativo e as instituições do poder local; já em Curuçá, essa cooperação e essa complementaridade se tornaram objeto de debates desde a última eleição. 
o resultado das interferências da implementação de uma agenda das instâncias políticas nacionais para tratar da situação das chamadas populações tradicionais, em um contexto de ambientalização. Ela também é resultante da função cada vez mais política que assume o Conselho Deliberativo, cujos compromissos terminam por se impor - em razão das práticas deliberativas deles resultantes - como compromissos de caráter político, tendo em vista a existência de um acordo implícito entre os políticos eleitos e os membros do Conselho.

Essas mudanças, que interrogam o poder local, não são, a priori, significativas da emergência de uma nova forma de democracia, que poderia ser qualificada de ambiental, como é sugerido por Deborah de Magalhãs Lima (2002), ao refletir a experiência da participação na implementação de Reservas de Desenvolvimento Sustentável, outra categoria de Unidade de Conservação que contempla os direitos das populações tradicionais na iniciativa ambientalista. Trata-se, antes de tudo, do resultado de uma tentativa de integração das práticas deliberativas que inspiram o funcionamento do Conselho e os compromissos dos conselheiros no sistema de poder local de tipo representativo. Assim sendo, do mesmo modo que o desenvolvimento territorial, já referi: : um modelo, e sim a um processo dinâmico de mobilização de atores e recursos, essas tentativas de integração de práticas deliberativas, no sistema institucional local, dizem respeito ao resultado de uma construção que se processa por ajustamentos permanentes, conforme es$\stackrel{2}{\wedge}$ tratégias dos atores envolvidos e as alianças e $\dot{A}$ acordos que conseguem negociar. Tal construจิ ção escapa também da ideia de modelo. O fato

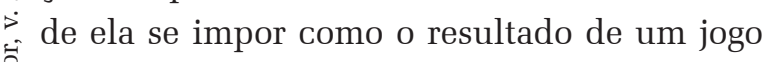
de atores que trabalham no âmbito de uma parceria deliberativa e estão implicados em diferentes instâncias de decisão justifica, então, que se faça referência à ideia de governança territorial para compreender o modo como se administra a sociedade local em emergência
(Teisserenc, 2014). E, mais importante ainda: na medida em que a maior parte das mudanças tem sua legitimidade conferida pela questão ambiental, faz sentido se falar em governança territorial ambiental.

Dessa maneira, podemos considerar essas novas práticas administrativas do território, na forma de uma governança ambiental, como constituintes das premissas de um novo modelo de desenvolvimento, como é sugerido por Deborah de Magalhães Lima? No ponto a que nossas investigações chegaram, nada nos permite afirmar, ao mesmo tempo em que nada justifica rejeitar essa possibilidade. Portanto, conservaremos essa ideia como hipótese de trabalho, uma vez ser ainda cedo para avaliar os resultados das experiências das Resex, especificamente, as marinhas do estado do Pará.

Recebido para publicação em 10 de janeiro de 2016 Aceito em 23 de abril de 2016

\section{REFERÊNCIAS}

ALLEGRETTI, Mary. A construção social de políticas públicas: Chico Mendes e o movimento dos seringueiros. Desenvolvimento e meio ambiente, Paraná, n. 18, p 39-59, jul./dez. 2008.

ALMEIDA, Mauro William Barbosa de. Direitos à floresta e ambientalismo: os seringueiros e suas lutas. Revista Brasileira de Ciências Sociais, São Paulo, v. 19, n. 55, p 33-53, 2004.

AUBERTIN, Catherine; PINTON, Florence. De nouvelles frontières du développement durable : la construction des espaces de droits en Amazonie brésilienne. In : ALBALADEJO, Christophe ; TULET, Jean-Christian (Org.). Fronts pionniers de l'Amazonie brésilienne. Paris: l'Harmattan, 2006.

BERNO DE ALMEIDA, AlfredoWagner. Antropologia dos archivos da Amazônia. Rio de Janeiro: Casa 8 / F.U.A, 2008.

BOYER, Véronique. Une forme d'africanisation au Brésil - les quilombolas entre recherche anthropologique et expertise politico-légale. Cahiers d'Études Africaines, EHESS, 2010/2, N. 198-199-200, p. 707-730.

BRASIL. Lei no 9.985, de 18 de julho de 2000. Regulamenta o art. 225, § 1o, incisos I, II, III e VII da constituição federal, institui o sistema nacional de unidades de conservação da natureza e dá outras providências. Diário Oficial [da] União,Brasília, DF,19 jul. 2000.

BRASIL. Decreto $\mathrm{n}^{\circ}$ 6.040, de 07 de fevereiro de 2007. Institui a política Nacional de desenvolvimento sustentável dos povos e comunidades tradicionais. Diário Oficial [da] Uniẫo,Brasília, DF, 08 fev. 2007. 
CAPOBIANCO, João Paulo et al. (Org.). Biodiversidade na Amazônia Brasileira: avaliação e ações prioritárias para a conservação, uso sustentável e repartição de benefícios'. São Paulo: Estação Liberdade - Instituto Socioambiental, 2001.

CARNEIRO DA CUNHA, Manuela. Populacões tradicionais e conservação ambiental. In: CAPOBIANCO, João Paulo et al. (Org.). Biodiversidade na Amazônia Brasileira: avaliação e ações prioritárias para a conservação, uso sustentável e repartição de benefícios’. São Paulo: Estação Liberdade - Instituto Socioambiental, 2001. p.184-193.

GOHN, Maria da Glória. Conselhos gestores e participação sócio-política. São Paulo: Cortez, 2007.

GREFFE, Xavier. Le développement local. Paris : Editions de l'Aube, 1984.

HABERMAS, Jurgen. Théorie de l'agir communicationnel. Paris: Fayard,1987

HONNETH, Axel. La dynamique sociale du mépris. D'où parle une théorie critique de la société ? In: BOUCHINDHOMME, Christian; ROCHLITZ, Rainer (Dir.). Habermas, la raison, la critique. Paris: Le Cerf, 1996.

LAGROYE, Jacques (Org.) La politisation. Paris: Belin, 2003.

LASCOUMES, Pierre; LE GALES, Patrick. Gouverner par les instruments. Paris: les presses de science po,2007.

LEFF, Enrique. Racionalidade ambiental. A reapropriaçao social da natureza. Rio de Janeiro: Civilizaçao Brasileira, 2006.

LÉNA, Philippe. As políticas de desenvolvimento sustentável para a Amazônia: problemas e contradiçoes. Boletim Rede Amazonia, Rio de Janeiro, Ano 1, n. 1, p. 9-20, 2002.
LOPES, Jose Sérgio Leite. Sobre processo de "ambientalizaçao" dos conflitos e sobre dilemas da participaçao. Horizontes Antropológicos, Porto Alegre, v. 12, n. 25, p. 31-64, 2006.

LIMA, Deborah de Magalhães. Éthique et politique environnementale en Amazonie contemporaine. Lusotopie, Paris, p. 13-23, 2002.

SANTILLI, Juliana. A proteção legal aos conhecimentos tradiconais associados à biodiversidade: o artigo 8(j) da convenção da diversidade biológica e as propostas para sua implementação no Brasil e em outros países. Doc. de trabalho. Brasília: ISA,2005.

TEISSERENC, Pierre. A governança territorial a partir da experiência das reservas Extrativistas. Revista PósCiências Sociais, Maranhão, v. 11, n. 22, p. 19-41, 2014.

TEISSERENC, Pierre. Les resexs: un instrument au service des politiques de développement durable en Amazonie brésilienne. Dossiê: Amazônia e paradigmas de desenvolvimento. Revista Pós Ciências Sociais, Maranhão, v. 6, n. 12 , p. 41-68, 2009

TEISSERENC, Pierre. Les politiques de développement local. $2^{\mathrm{a}}$ ed. Paris: Économica, 2002. (Collection Collectivités Territoriales).

VASCONCELOS, Aloma Tereza. Gestão pública e participação: uma análise do conselho deliberativo da reserva extrativista mãe grande de Curuçá. 2010.177 p. Dissertaçao (Mestrado) - Núcleo de Meio Ambiente, Universidade Federal do Pará , Belém, 2010. 


\section{POLITICIZATION, ENVIRONMENTALIZATION, AND TERRITORIAL DEVELOPMENT IN EXTRACTIVE RESERVES}

\author{
Maria José da S. A. Teisserenc
}

This article, based researches in the context of two marine extractive reserves in the state of Pará, Mãe Grande do Curuçá and São João da Ponta, deals with the changes that has been occurring in local power related to the creation of protected areas of Brazilian Amazon. It is observed, therefore, a politicization of the local challenges, manifested as the result of the work done in the deliberative council, in which the communities mobilization and the engagement of its leaders make debates, about the development of their territory according to environmental demands, possible. This is a significant dynamic of territorial development that benefits itself from a general environmentalization emerged with the creation of reserves and with the deliberative value of compromise of council directors with a political instance. This situation constitutes an interesting opportunity for the analysis of the relations as practices of local deliberative democracy and as an orientation of development that inspires the engagement of local agents in new institutions, such as the deliberative councils.

KeYwords: Politicization and public action. Territorial development. Environmentalization. Local power. Engagement and deliberation.

\section{POLITISATION, ENVIRONNEMENTALISATION ET DÉVELOPPEMENT TERRITORIAL DANS DES RÉSERVES EXTRATIVISTES}

\author{
Maria José da S. A. Teisserenc
}

Cet article, qui est l'aboutissement de recherches faites dans le contexte de deux Résex (Réserves extrativistes) marines de l'état du Para, Mãe Grande do Curuçá et São João da Ponta, analyse les changements opérés au sein du pouvoir local, en accord avec la création de zones protégées en Amazonie brésilienne. On observe alors une politisation des enjeux locaux qui se manifeste à la suite d'un travail réalisé par les Conseils Délibératifs dans lesquels la mobilisation des communautés et l'engagement de leurs représentants permettent des débats concernant le développement de leur territoire tout en respectant les exigences environnementales. Il s'agit d'une dynamique significative d'un développement territorial au bénéfice d'une environnementalisation générale qui a lieu grâce à la création des Réserves et à la valeur délibérative des engagements des membres conseillers en tant qu'organe politique. Cette situation constitue une occasion intéressante d'analyse des relations entre les pratiques de la démocratie locale de type délibératif et une orientation de développement qui inspire l'engagement des acteurs locaux dans des institutions nouvelles telles que les Conseils Délibératifs.

Mots-CLÉs: Politisation et action publique. Développement territorial. Environnementalisation. Pouvoir local. Participation et délibération.

Maria José da S. A. Teisserenc - Doutora Ciências Humanas. Professora da Faculdade de Ciências Sociais e do Programa de Pós Graduação em Sociologia e Antropologia da UFPA. Atua na orientação acadêmica e na pesquisa dentro do campo temático das ações coletiva e pública, território e ambiente, acompanhando dinâmicas de organização, relações com o poder local e participação em áreas protegidas na Amazônia brasileira. Dentro dessas áreas protegidas a atenção maior é dada aos Territórios quilombolas, Reservas Extrativistas e Reservas de Desenvolvimento Sustentável. Entre as publicações mais recentes registramse: Território de ação local e de desenvolvimento sustentável: efeitos da reivindicação socioambiental nas ciências sociais. In: Sociologia e antropologia, Revista do Programa de Pós-Graduação em Sociologia e Antropologia da Universidade Federal do Rio de Janeiro. V. 04, n. 1 (junho de 2014). Artigo escrito como co-autora do professor Pierre Teisserenc; Ação local, território e serviço público de saúde: os TeneteharTembé entre a diferenciação e a universalização. In: Revista Pós-Ciências Sociais, PPGCSoc/UFMA, v. 11, n. 21, jan/jun 2014. Artigo escrito como co-autora da também professora da UFPA, Vanderlúcia da Silva Ponte; Territórios socioambientais em construção na Amazônia brasileira. Organizadores: Neide Esterci, Horácio Antunes de Sant'Ana Júnior e Maria José da Silva Aquino Teisserenc (Orgs). 1 ed. Rio de Janeiro: 7 Letras, 2014. Coleção Sociologia e Antropologia; Atores não-governamentais, relações, representações e desafios (na Amazônia brasileira). In: Territórios socioambientais em construção na Amazônia brasileira. Organizadores: Neide Esterci, Horácio Antunes de Sant’Ana Júnior e Maria José da Silva Aquino Teisserenc (Orgs). 1 Ed. Rio de Janeiro: 7 Letras, 2014. Coleção Sociologia e Antropologia. p.73-104. 